\title{
Supramolecular Control of Spin Crossover Phenomena Using Various Amphiphiles
}

\author{
Keita Kuroiwa \\ Department of Nanoscience, Faculty of Engineering, Sojo University, Kumamoto 860-0082, Japan; \\ keitak@nano.sojo-u.ac.jp; Tel.: +81-96-326-3891 \\ Academic Editor: Kazuyuki Takahashi \\ Received: 27 June 2017; Accepted: 12 July 2017; Published: 14 July 2017
}

\begin{abstract}
An aspect of nanochemistry that has attracted significant attention is the formation of nanoarchitectures from the self-assembly of metal complexes, based on the design of compounds having cooperative functionalities. This technique is currently seen as important within the field of nanomaterials. In the present review, we describe the methods that allow tuning of the intermolecular interactions between spin crossover (SCO) complexes in various media. These approaches include the use of lipophilic derivatives, lipids, and diblock copolypeptide amphiphiles. The resulting supramolecular assemblies can enhance the solubility of various SCO complexes in both organic and aqueous media. In addition, amphiphilic modifications of coordination systems can result in metastable structures and dynamic structural transformations leading to unique solution properties, including spin state switching. The supramolecular chemistry of metal complexes is unprecedented in its scope and potential applications, and it is hoped that the studies presented herein will promote further investigation of dynamic supramolecular devices.
\end{abstract}

Keywords: SCO; nanoarchitecture; self-assembly; metastable; gel; film; nanofiber; nanorod; nanorectangular; supramolecule

\section{Introduction}

The self-assembly and integration of functional metal complexes has attracted significant attention due to the potential for the development of useful molecular systems [1]. Naturally-occurring examples of such systems include the metal complexes that play important roles in various biological functions, such as the transportation of oxygen, gene activation, and the catalytic reactions of enzymes [2,3]. The field of biomimetic chemistry aims both to understand and to utilize the functional reactions and properties of metal complexes, and includes studies of the intermolecular and intramolecular interactions among naturally-occurring metal complexes with specific functions. However, to date, our knowledge of self-assembly on the molecular level has been largely limited to chemical structures composed of only one type of molecule.

Despite this lack of understanding, there are numerous examples of the supramolecular self-assembly of metal complexes, including in molecular crystals [4], colloids [5], monolayers [6], helices [7], grids [8], polymers [9] and metal-organic frameworks (MOFs) [10-12]. Most molecular self-assemblies result from the spontaneous aggregation of molecules under thermodynamic equilibrium conditions into stable, structurally-defined aggregates connected by relatively strong non-covalent forces such as hydrogen bonding and electrostatic interactions [13]. The more complex self-assembly of both metal complexes and organic compounds, which can result in the supramolecular control of various functions, is controlled by stronger interactions such as covalent bonding and coordination and also by weak interactions, including hydrogen bonding, hydrophobic interactions, and van der Waals interactions [13-15]. Of these, the non-covalent interactions are expected to play an important role in the supramolecular control of coordination systems. 
Self-assembly depends on the specific properties of the main components of the system, including electronic states, nanostructures, and bulk physical characteristics. As such, the interactions between components can be adjusted by selecting component-specific properties [16]. As an example, moderately-strong interactions and suitable binding constants result in dynamic systems that exhibit reversibility and the potential for self-growth and self-propagation. These assemblies are often referred to as non-equilibrium structures or metastable structures. It is therefore apparent that the self-assembly of molecules will be affected by the properties of the compounds and that these systems may also be responsive to external stimuli.

Spin crossover (SCO) complexes have been investigated within the fields of coordination chemistry and supramolecular chemistry, as well as in other areas of chemistry and physics. The coordination geometry of metal complexes both determines the structure of the assembly and modifies the electronic configuration of the d-electrons of the metal. Strong interactions between ligands and metal ions will result in significant splitting of the d-orbitals, leading to low spin (LS) states. Conversely, weak interactions will give rise to high spin (HS) compounds. If the interaction is of intermediate strength and is responsive to external stimuli, it can be possible to switch from one spin state to the other. Of particular interest are low-dimensional metal complexes [17-48], in which metals are bridged by linear bidentate ligands, and supramolecular three-dimensional crystals [49-54] with cooperative structural transformations, which are sometimes capable of hosting various molecules. Both represent high priorities with regard to the investigation of supramolecular coordination compounds. In addition, low-dimensional coordination polymers and coordination systems have been examined as a means of generating multi-functional materials. In particular, supramolecular assembly-disassembly is a necessary condition for self-integration, self-propagation, and adaptive behavior. Finally, it is also possible to tune the interaction strength over a wide range, from weak to strong. In addition, the change in the spin state can affect both the magnetic and optical properties of the complex.

Since amphiphilic technique was attempted [17], the preparation of supramolecular formations of amphiphiles incorporating SCO complexes using the Langmuir-Blodgett (LB) technique has been reported [18-20]. This approach can produce interesting materials because of its ability to organize molecules in multilayered architectures. In addition, Kurth et al., Kimizuka et al. and Aida et al. have all studied one-dimensional supramolecular assemblies of SCO complexes and demonstrated organogels and films that exhibit aggregation-induced SCO phenomena, providing evidence that such assemblies possess different characteristics compared to the metal complexes in the bulk state [21-23]. Subsequent to reports of these functional self-assembling systems, many chemists and physicists began to examine low-dimensional self-assemblies and low-dimensional coordination systems involving SCO complexes. However, to date, almost all supramolecular systems based on low-dimensional compounds have relied on strong interactions such as covalent bonding and coordination, and the properties of the resulting supramolecules have been similar to those of the original metal complexes in the solid state (Figure 1a).

Recently, our group developed a flexible supramolecular system composed of metal complexes, using both lipophilic and amphiphilic compounds [24-35] (Figure 1b,c). This system exhibited tunable, metastable properties, such as the formation of heat-set gel-like networks $[25,26]$ and supramolecular SCO via adaptive molecular clefts [27], that are not observed in the solid state. The design of supramolecular systems such as these is predicted to lead to the fabrication of flexible, stimuli-responsive supramolecules with unique and specific functions, and is also expected to improve our understanding of multi-functional biomimetic systems.

In this review, we briefly describe the chemical structures and properties that result in flexible supramolecular systems, focusing on the use of lipophilic amphiphiles [27], lipid amphiphiles (Figure 1b) [29], and diblock copolypeptide amphiphiles (Figure 1c) [36,37]. The important roles that flexibility and weak interactions play in the supramolecular control of nanostructure morphologies and in the generation of dynamic, metastable functions involving SCO phenomena are also discussed, based on the most recent findings of our research group. 
a)

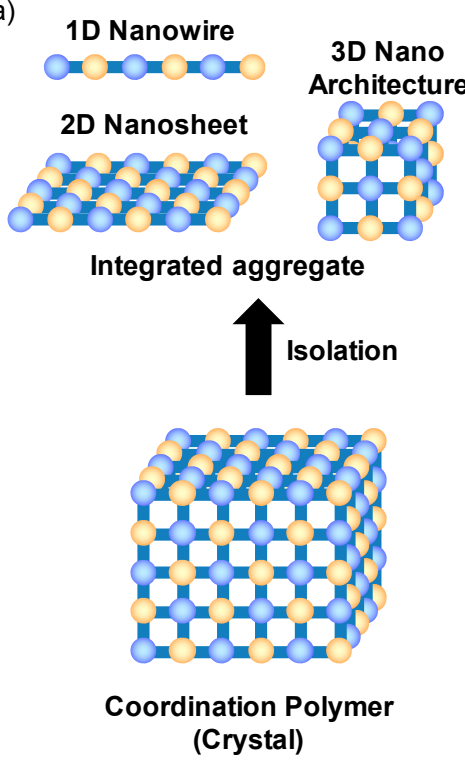

b)
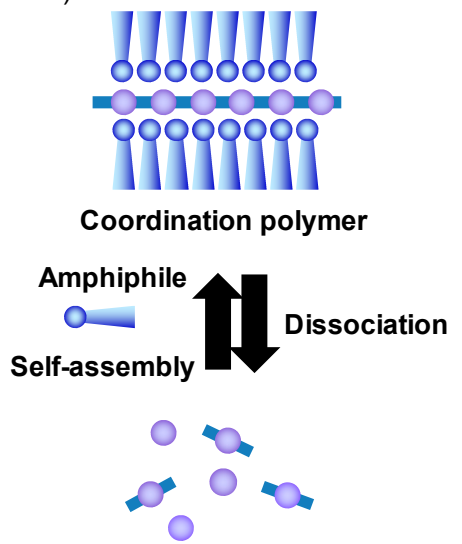

Monomeric complexes (Polynuclear complexes) c)
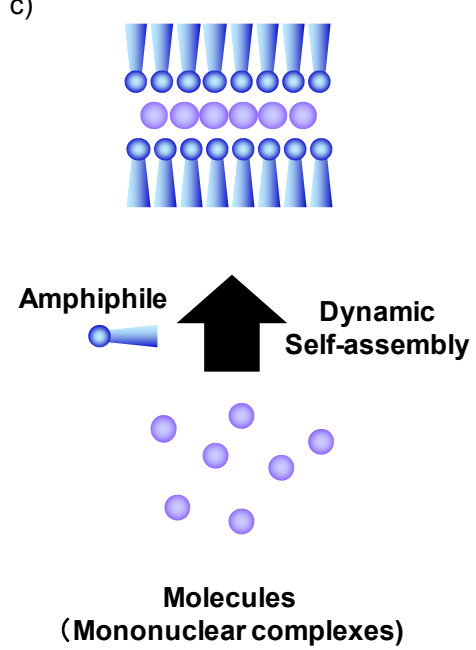

Figure 1. Illustrations showing (a) the isolation of various structures from a polymer crystal; (b) the self-assembly of a coordination polymer; and (c) the integration of amphiphilic molecules, all of which represent means of constructing nanoassemblies of SCO complexes.

\section{Self-Assembly of Amphiphilic and Lipophilic $\mathrm{Fe}^{\mathrm{II}}$ 1,2,4-Triazole Complexes}

It is known that 1,2,4-triazoles are able to act as bridging ligands, and linear metal complexes of these compounds have been actively investigated due to their polymeric structures and their magnetic interactions with linearly-aligned metal ions [38-44]. As an example, a series of oligonuclear compounds based on $\mathrm{Mn}, \mathrm{Fe}, \mathrm{Co}, \mathrm{Ni}$ and $\mathrm{Zn}$ has been prepared, all of which have been found to undergo antiferromagnetic interactions [42-44]. The most interesting feature of these compounds is their characteristic SCO switching between LS (purple, $S=0$ ) and HS (colorless, $S=2$ ) states [38-44]. In addition, as a result of their magnetic properties, these complexes are obvious candidates for use as information storage materials. In particular, $\mathrm{Fe}^{\mathrm{II}}$ 1,2,4-triazole complexes have the advantages of ease of synthesis and the ready formation of bridged structures. Despite this, because these compounds are generally only obtained as powders, a remaining challenge is to develop processes to obtain ultrathin films and other delicate structures required for device applications. To date, preliminary studies of triazole complexes have been limited to the study of bulk powder samples, and there has been no general methodology developed for the conversion of these materials to nanostructures. One aspect of the development of such complexes that is theoretically possible is the tuning of their magnetic properties, based on supramolecular control of the spatial arrangements of the metal ions and triazole ligands, resulting in magnetic cooperation between metal complexes.

\subsection{4-Alkylated 1,2,4-Triazole Complexes}

Working towards the development of supramolecular triazole complexes, we initially introduced a solvophilic dodecyloxypropyl chain within the ligand [22]. These chains made it possible to dissolve metal complexes containing the lipophilic triazole ligand $\mathbf{1}$ in organic media. To date, several lipophilic triazole complexes have been reported [17,20,22,23,43-48]. However, it is noteworthy that LS complexes incorporating these ligands are unstable in the solid state or in organogels, since van der Waals interactions between the rigid alkyl chains increase the Fe-to-Fe distance and consequently promote conversion to the HS state. When designing advanced supramolecular systems, it is therefore necessary to consider the chemical composition of the triazole ligands and to carefully select the appropriate media along with suitable external conditions and stimuli, such as temperature, redox reactions, and molecular recognition interactions. 
Our own work has focused on the development of flexible, lipophilic, transition metal-triazole complexes in the form of organic solvent solutions [25-28], thin films [27], and liquid crystals [31]. As an example, the flexible ether linkage in triazole ligand $\mathbf{1}$ enhances the solubility of the metal complexes in organic media and tailors the packing of the alkyl chains (Figure 2). Flexible metal complexes such as these undergo a variety of interactions with organic media, organic molecules, and liquid crystals, and the present review examines the coordination structures, magnetic properties, and morphological dynamism of these complexes.
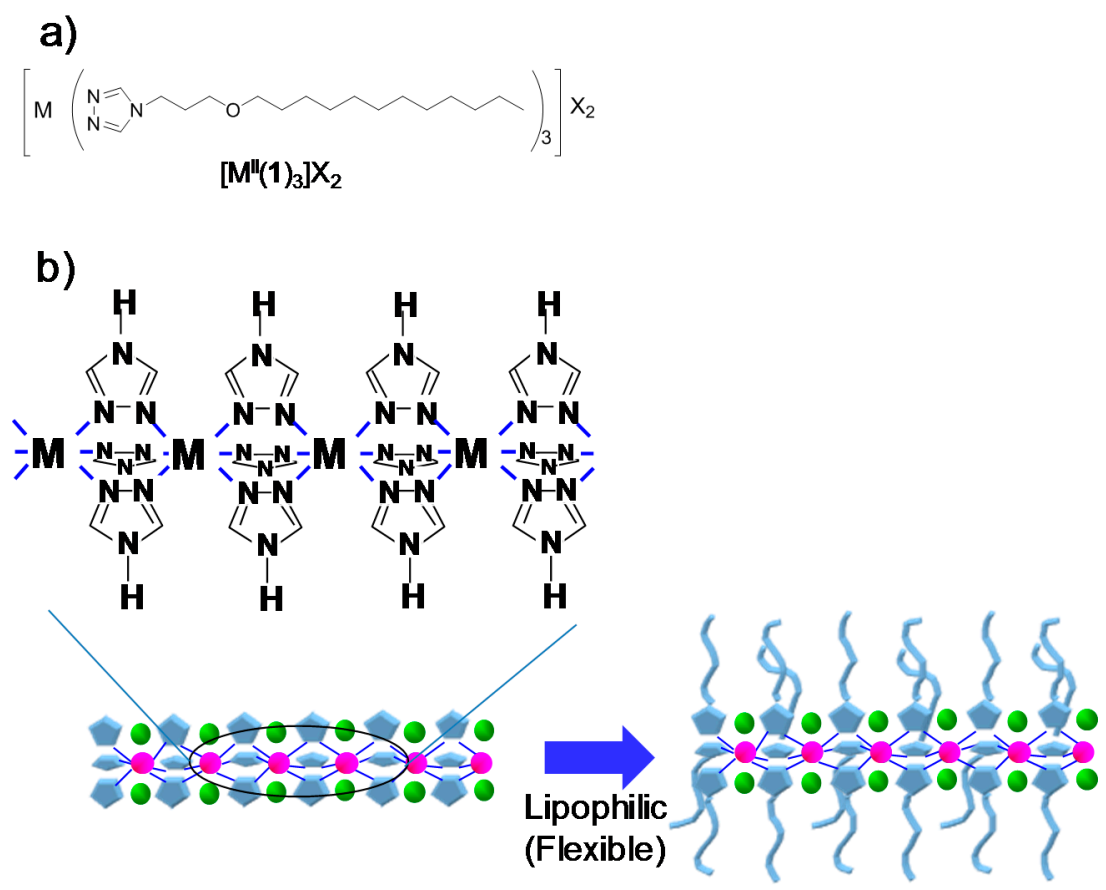

Figure 2. (a) Chemical structures of $\left[\mathrm{Fe}^{\mathrm{II}}(\mathbf{1})_{3}\right] \mathrm{Cl}_{2}$ and (b) illustrations of $\left[\mathrm{Fe}^{\mathrm{II}}(\mathbf{1})_{3}\right] \mathrm{Cl}_{2}$ showing the flexible alkyl chains.

The interactions between alcohols and the surfaces of linear triazole complexes have been employed as a mean of controlling the $\mathrm{SCO}$ of the $\left[\mathrm{Fe}^{\mathrm{II}}(\mathbf{1})_{3}\right] \mathrm{Cl}_{2}$ complex [27]. This material is a purple powder when in its solid form at ambient temperature, which is typical of such complexes in their LS state. However, the complex transitions to a pale yellow organogel (the HS state) when dissolved in chloroform. Such gels result from the formation of nanofiber aggregates, as has been confirmed by transmission electron microscopy (TEM). The casting of a chloroform solution of this type of complex onto solid substrates results in transparent purple films, in which the complex is once again in the LS state. These cast films exhibit sluggish SCO (LS $\rightleftarrows H S$ ) in response to temperature changes, without thermal hysteresis (Figure 3a). In contrast, the co-casting of equimolar quantities of dodecanol or tetradecanol with $\left[\mathrm{Fe}^{\mathrm{II}}(\mathbf{1})_{3}\right] \mathrm{Cl}_{2}$ forms composite films in which alcohol molecules are bound to the complex by ionic hydrogen bonding between the hydroxyl groups of the alcohols and the chloride ions, as well as by van der Waals interactions. At room temperature, these cast films have regular lamellar structures either with or without doping with alcohol, as determined by wide angle X-ray diffraction (WAXD) measurements. Interestingly, binary films made from $\left[\mathrm{Fe}^{\mathrm{II}}(\mathbf{1})_{3}\right] \mathrm{Cl}_{2}$ and long chain alcohols (containing 12 or 14 carbons) exhibit reversible and abrupt SCO on heating with thermal hysteresis (Figure 3a). The evident bistability of these films is closely related to dynamic structural transformations between lamellar and hexagonal structures, suggesting a novel supramolecular strategy for controlling the bistability of SCO phenomena (Figure 3b) [27]. 


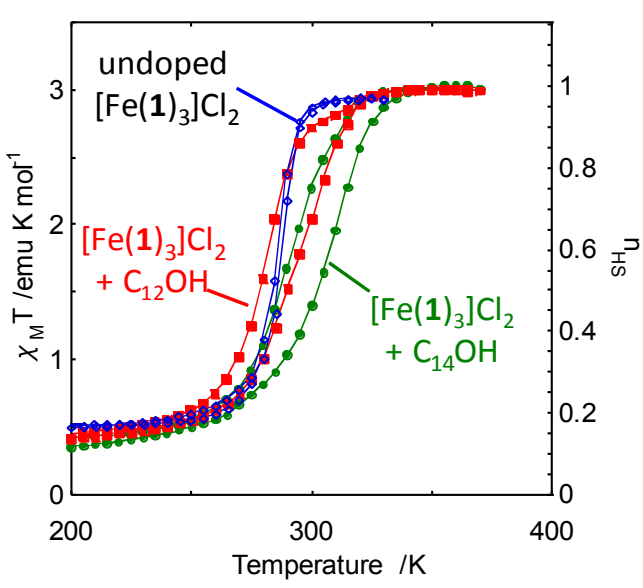

(a)

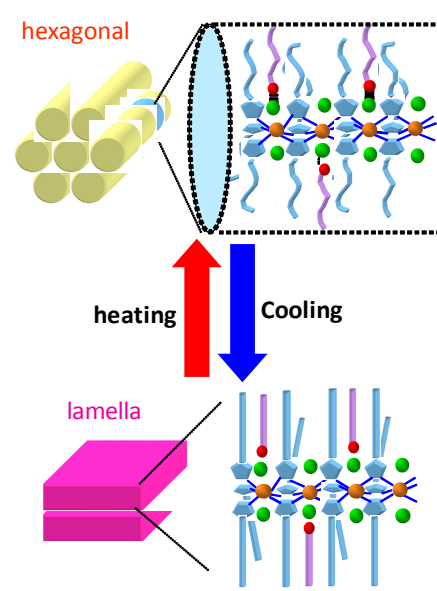

(b)

Figure 3. (a) The temperature dependence of the magnetic susceptibility of $\left[\mathrm{Fe}^{\mathrm{II}}(\mathbf{1})_{3}\right] \mathrm{Cl}_{2} / \mathrm{C}_{n} \mathrm{OH}$ samples ( $n=12$ and 14) and (b) an illustration of the supramolecular unit structures in the cast films. The samples undergo a dynamic structural transformation between lamellar (at $298 \mathrm{~K}$ ) and hexagonal structures (at 373 K). Adapted with permission from J. Polym. Sci. A: Polym. Chem. 2006, 44, 5192-5202. Copyright (C) 2006 Wiley Periodicals, Inc.

In order to derive functional systems through imparting spin-based functionality to guest molecules, we have demonstrated the formation of liquid crystal gels from mixtures of linear $\mathrm{Fe}^{\mathrm{II}}-1,2,4$-triazole complexes and nematic liquid crystals [31]. JC-1041XX and JD-1002XX were employed as the liquid crystals, since both display nematic liquid crystal phases over a wide temperature range (T/K of phase transitions: K 291.1 N 365.2 I (JC-1041XX); K 276.8 N 347.9 I (JD-1002XX), Figure 4a). The purple color of the resulting gels indicates that the $\left[\mathrm{Fe}^{\mathrm{II}}(\mathbf{1})_{3}\right] \mathrm{Cl}_{2}$ complex adopts the LS configuration in either JC-1041XX or JD-1002XX, in contrast to the HS gels formed in chloroform [27]. At elevated temperatures, the macroscopically homogeneous gel structure is preserved, although the color changes from purple to pale yellow. This color change is thermally reversible, as shown by the temperature dependence of reflectance spectra. In addition, the temperature dependence of the magnetic susceptibility demonstrates that the liquid crystal gel composed of $\left[\mathrm{Fe}^{\mathrm{II}}(\mathbf{1})_{3}\right] \mathrm{Cl}_{2}$ and JC-1041XX exhibits SCO at elevated temperatures, with the appearance of thermal hysteresis. The SCO temperature during the heating cycle (for $\mathrm{LS} \rightarrow \mathrm{HS}, \mathrm{T}_{\mathrm{sc}} \uparrow$, the temperature at which half of the transitioning $\mathrm{Fe}^{\mathrm{II}}$ changes spin) is approximately $334 \mathrm{~K}$, which is higher than that observed in the cooling cycle (HS $\rightarrow$ LS, $\mathrm{T}_{\mathrm{sc}} \downarrow, 324 \mathrm{~K}$, Figure $4 \mathrm{a}$ ). Similarly, a combination of $\left[\mathrm{Fe}^{\mathrm{II}}(\mathbf{1})_{3}\right] \mathrm{Cl}_{2}$ and JD-1002XX exhibits a higher SCO temperature during heating as opposed to cooling (324 K compared to $319 \mathrm{~K})$. These binary $\left[\mathrm{Fe}^{\mathrm{II}}(\mathbf{1})_{3}\right] \mathrm{Cl}_{2} /$ liquid crystal composites therefore undergo sluggish SCO transitions with thermal hysteresis within a higher range of temperatures as compared to pure $\left[\mathrm{Fe}^{\mathrm{II}}(\mathbf{1})_{3}\right] \mathrm{Cl}_{2}$, for which both $\mathrm{T}_{\mathrm{sc}} \uparrow$ and $\mathrm{T}_{\mathrm{sc}} \downarrow$ are $300 \mathrm{~K}$ [27]. To date, the behavior of one-dimensional $\mathrm{Fe}^{\mathrm{II}}$ complexes of 4-substituted 1,2,4-triazoles and their SCO characteristics have been studied with these compounds solely in the solid state or as organogels [45-48]. In contrast, the systems formed from combinations of lipophilic $\mathrm{Fe}^{\mathrm{II}}$ complexes and hydrophobic liquid crystals have several advantages due to the considerable effects of the liquid crystal environment on either the solvophobic compaction of the N-Fe coordination bonds or the destabilization of the HS state due to the reduction of the $\mathrm{Fe}-\mathrm{Fe}$ distance (Figure 4b) [45]. Composites consisting of liquid crystal and organic (and/or polymeric) molecules have also been reported to have advantageous properties because of the unique interaction that results from the bicontinuous phase separation structures in these mixtures. These bicontinuous structures are formed when the organic components are suitably miscible with the liquid crystals. Molecular assemblies of functional low molecular weight gelators have also been found to form liquid crystal gels. It is anticipated that the incorporation of functional components such as lipophilic triazole 
complexes in these liquid crystal hybrids will allow the development of intelligent soft materials by imparting spin-based functionalities and solvophobic interactions.

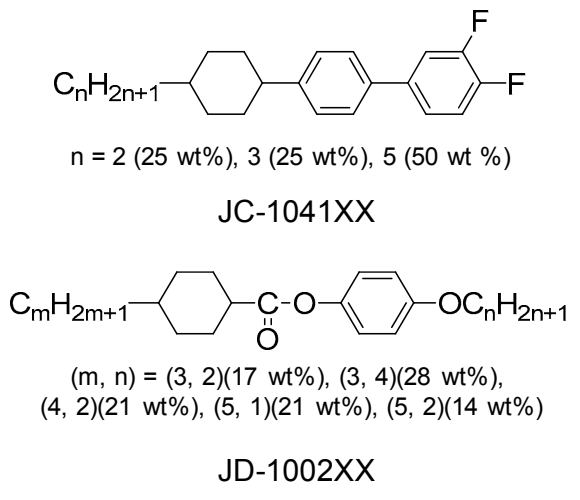

(a)

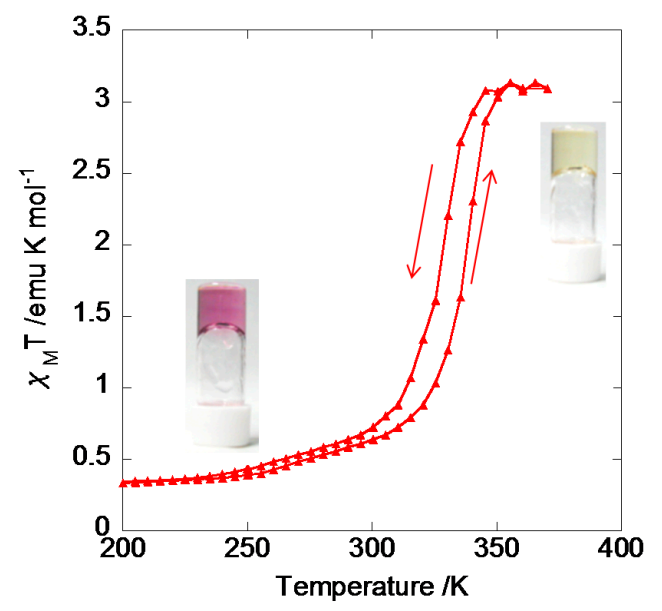

(b)

Figure 4. (a) The chemical structures of the liquid crystals JC-1041XX and JD-1002XX and (b) the temperature dependence of the magnetic susceptibility of a $\left[\mathrm{Fe}^{\mathrm{II}}(\mathbf{1})_{3}\right] \mathrm{Cl}_{2} / \mathrm{JC}-1041 \mathrm{XX}$ liquid crystal gel. The inset photographs are of the gel at $293 \mathrm{~K}$ (left) and $363 \mathrm{~K}$ (right). Adapted with permission from Chem. Commun. 2010, 46, 1229-1231. Copyright (c) 2010, Royal Society of Chemistry.

\section{2. $4 R-1,2,4-T r i a z o l e ~ C o m p l e x e s$ with Lipid Amphiphiles}

The lipid-Fe ${ }^{\mathrm{II}}$ triazole complexes developed in the present study are shown in Figure 5 [29]. In contrast to the conventional design of 4-alkylated 1,2,4-triazoles, an L-glutamate-derived lipid was introduced as a lipophilic counter anion, and 4-amino-1,2,4-triazole $\left(\mathrm{NH}_{2}\right.$ trz) and 4-(2-hydroxyethyl)-1,2,4-triazole ( $\mathrm{HOC}_{2}$ trz) were employed as triazole ligands. This noncovalent introduction of a lipophilic moiety is suitable in the case of 1,2,4-triazole-based SCO complexes since the covalent modification of triazole ligands with bulky substituents generally lengthens the Fe-ligand bonds, resulting in the destabilization of LS states [45].

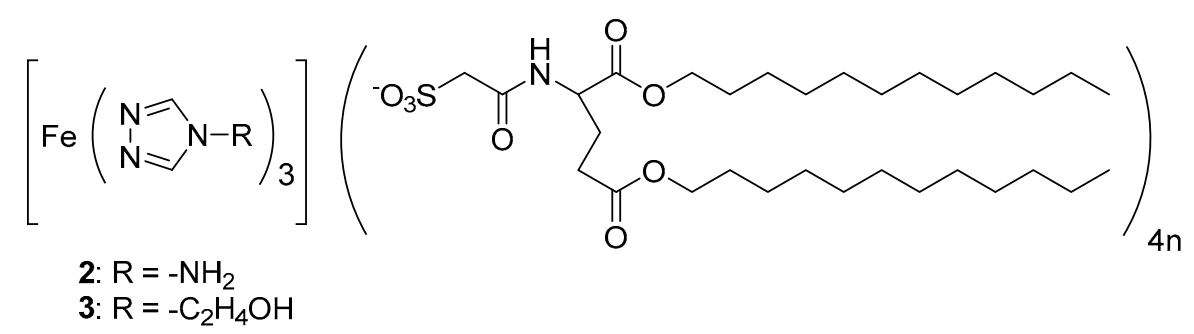

Figure 5. Structures of the lipid-Fe ${ }^{\mathrm{II}}$ triazole complexes consisting of an L-glutamate-derived lipid and 4-amino-1,2,4-triazole ( $\mathrm{NH}_{2}$ trz) (2) or 4-(2-hydroxyethyl)-1,2,4-triazole (HOC2trz) (3).

The complexes of 2 and 3 were dispersed in toluene with heating at concentrations of 5 or $20 \mathrm{mM}$. Unexpectedly, toluene dispersions of 2 were purple at room temperature, indicating that the LS state of the complex was maintained in solution (see the photographic image acquired at $298 \mathrm{~K}$ in Figure 6a) [29]. Figure 6a also presents the temperature dependence of the absorption spectra obtained from complex 2 ( 5 unit $\mathrm{mM}$ in toluene). The absorption bands around 400 and $800 \mathrm{~nm}$ are assigned to $\mathrm{d}-\mathrm{d}$ transitions of the LS complex $\left({ }^{1} \mathrm{~A}_{1} \rightarrow{ }^{1} \mathrm{~T}_{1}\right)$ and the HS complex $\left({ }^{5} \mathrm{~T}_{2} \rightarrow{ }^{5} \mathrm{E}\right)$, respectively [45]. The absorbance at $540 \mathrm{~nm}$ (associated with the LS state) is decreased upon heating and is accompanied by an increase in the absorption intensity at $800 \mathrm{~nm}$ (HS state). These spectral changes were found to be 
completely reversible upon temperature cycling (Figure 6b). Lipid complex 3 also exhibited reversible thermal spectral changes in a lower temperature range (Figure 6b). The $\mathrm{T}_{\mathrm{sc}}$ values were ca. $300 \mathrm{~K}$ for 2 and $278 \mathrm{~K}$ for 3 . The thermally induced changes in spin state observed in the case of the toluene dispersions were compared with those in the solid state, and these same complexes in powder form had $\mathrm{T}_{\mathrm{sc}}$ values of $280 \mathrm{~K}$ for 2 and $170 \mathrm{~K}$ for 3 (see the SQUID data in Figure $6 \mathrm{~b}$ ). The $\mathrm{T}_{\mathrm{sc}}$ value of 2 in toluene was therefore increased by ca. $20 \mathrm{~K}$ compared to that of the solid state, indicating stabilization of the LS state in solution. In contrast, 3 in toluene showed a much higher $\mathrm{T}_{\mathrm{sc}}$ in solution (278 K) compared to that of the solid sample (170 K; Figure 6b). These observations are directly opposite to the typical finding that the LS configuration is destabilized in solution $[22,27,28]$. In addition, the occurrence of more abrupt spin state changes in solution is extraordinary because, in solution, changes in spin states are governed by spin equilibrium and so spin state transitions tend to occur gradually. This remarkable stabilization of LS states in solution suggests an increase in the ligand-field splitting energies compared to those in the crystalline states. In toluene, these ionic $\mathrm{Fe}^{\mathrm{II}}$ triazole complexes are dispersed with the help of solvophilic lipid alkyl chains. However, the solvophobic triazole complexes will tend to minimize contact with the nonpolar solvent molecules by contracting Fe-N bonds and/or nearest neighbor Fe-Fe distances (that is, by solvophobic compaction). Evidence for this effect is provided by the dependence of the SCO temperature on solvent polarity. In contrast, these solvophobic interactions do not take place in the solid state, and the packing of the lipid sulfonate groups in crystalline structures may not be dense enough to stabilize the LS complexes [29].

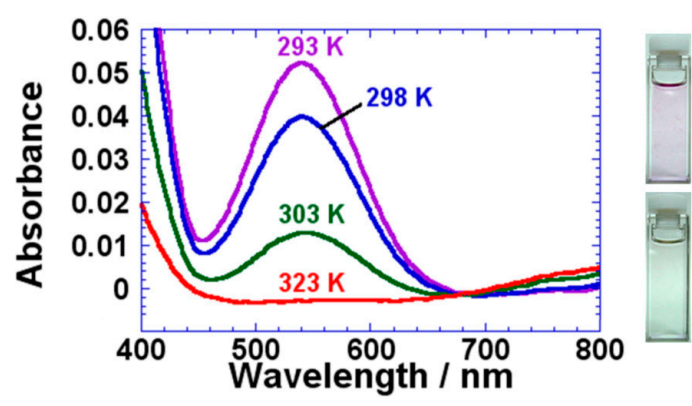

(a)

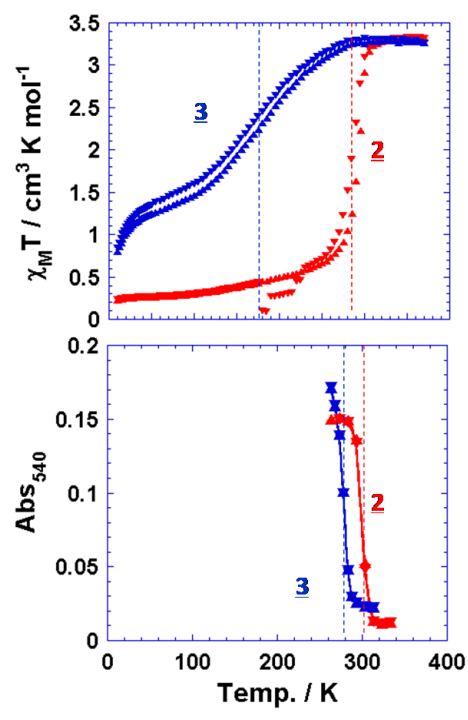

(b)

Figure 6. (a) Temperature dependence of the UV/vis absorption spectra of complex 2 (5 unit $\mathrm{mM}$ in toluene, on cooling) and photographs of 2 in toluene dispersions ( 5 unit mM) at $273 \mathrm{~K}$ (upper) and $298 \mathrm{~K}$ (lower); and (b) temperature dependences of peak absorption intensities at $540 \mathrm{~nm}$ (LS complex) for 2 and 3. Absorbance changes on heating and cooling cycles are plotted on the same curves. Adapted with permission from J. Am. Chem. Soc. 2008, 130, 5622-5623. Copyright 2008 American Chemical Society.

Atomic force microscopy (AFM) images of complexes 2 and 3 spread from dilute toluene dispersions at various temperatures are provided in Figure 7 [29]. Fibrous nanostructures with widths of 20-30 nm and heights of ca. $7 \mathrm{~nm}$ are abundant in the case of 2 in the LS state (Figure 7a). As the bimolecular length of the lipid is ca. $4.4 \mathrm{~nm}$ (based on a CPK model), these nanofibers evidently consist of bundled supramolecular complexes. In contrast, aggregates of fragmented structures (Figure $7 \mathrm{~b}$ ) are observed for the HS complex. The presence of nanofibers after cooling of the heat dispersed samples (Figure 7a) and the recovery of LS complexes (Figure 6) clearly indicate the reversible 
self-assembly of HS fragments into the original LS nanofibers. This effect is further supported by the copolymerization of $\mathbf{2}$ that occurs after cooling the heat-dissociated mixtures. Because SCO does not change the coordination number of the central atom in the complex, changes in spin state involving the disintegration of coordination bonds would be better described as spin conversion induced by self-assembly. These data demonstrate that lipid-packaged nanowires of $\mathrm{Fe}^{\mathrm{II}}$ triazole complexes display spin conversion characteristics in organic media. Abrupt spin conversion is observed due to the lipid-assisted solvophobic stabilization of LS complexes, SCO, and the reversible dissociation of coordination main chains. This solvophobic enhancement of ligand-metal interactions and the potential for synergistic control based on self-assembly are expected to expand the possibilities of coordination polymer chemistry.

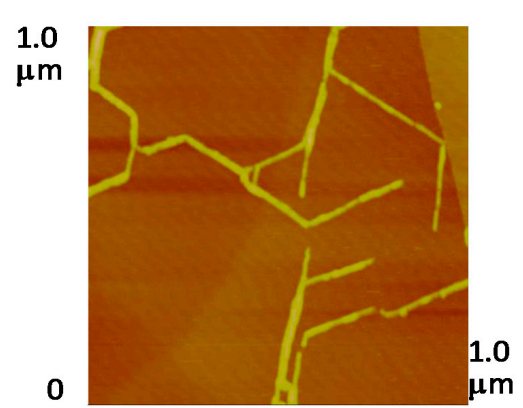

(a)

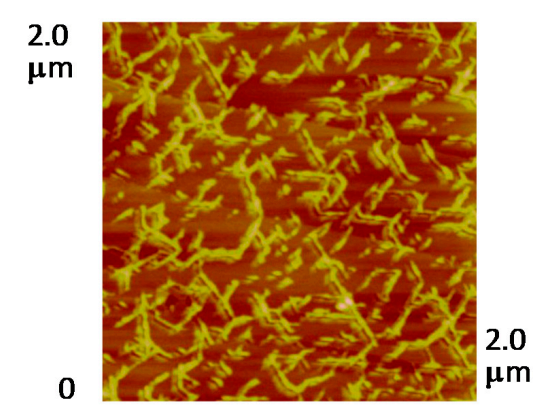

(b)

Figure 7. AFM images of complex 2 cast from toluene dispersions (50 unit $\mu \mathrm{M}$ ) on highly oriented pyrolytic graphite (HOPG) (a) at ambient temperature (LS state) and (b) at $313 \mathrm{~K}$ (HS state). Reprinted Adapted with permission from J. Am. Chem. Soc. 2008, 130, 5622-5623. Copyright 2008 American Chemical Society.

\section{Self-Assembly of Metal Complexes with Diblock Copolypeptide Amphiphiles}

The SCO of many mononuclear metal complexes also involves a spin change. As an example, it is well-known that the discrete cobalt(II) compounds [Co(terpy) $\left.)_{2}\right] \mathrm{X}_{2} \cdot \mathrm{nH}_{2} \mathrm{O}$ (terpy $=2,2^{\prime}: 6^{\prime}, 2^{\prime \prime}$-terpyridine, $\mathrm{X}=$ halide, pseudohalide, $\mathrm{BF}_{4}{ }^{-}, \mathrm{NO}_{3}{ }^{-}$or $\mathrm{ClO}_{4}{ }^{-}$and $\mathrm{n}=0$ to 5 ) have demonstrated gradual SCO behavior. Recently, the high molecular weight alkylated cobalt(II) compounds [Co(R-terpy $\left.)_{2}\right]\left(\mathrm{BF}_{4}\right)_{2}$ (R-terpy $=4^{\prime}$-alkoxy-2,2':6 $6^{\prime} 2^{\prime \prime}$-terpyridine) have been reported to display a "reverse spin transition" between HS and LS states with a thermal hysteresis loop and triggered by a structural phase transition [49-53]. It has been suggested that the flexibility of the alkyl chains in these complexes plays an important role in determining their unique magnetic properties, intermolecular interactions, and crystal properties. Ideally, the characteristics of such systems would be tunable by controlling the spatial arrangement of the SCO metal complexes, resulting in intermolecular interactions among the metal complexes using supramolecules without covalent or coordinative linkages.

\subsection{Co-Terpyridine Complexes with Diblock Copolypeptide Amphiphiles}

Our research group has also focused on combining cobalt(II) terpyridine complexes with diblock copolypeptide amphiphiles, and examining the SCO characteristics of the resulting complexes in water [36]. The diblock copolypeptide amphiphiles 4 and 5 and the polypeptide 6 (Figure 8) were synthesized. Compounds $\mathbf{4}$ and $\mathbf{5}$ were produced with a specific degree of polymerization intended to enhance the solubility of these compounds in water and also improve the packing of the polypeptides in supramolecular assemblies, resulting in the formation of hydrogels [55-58]. In contrast, polymer 6 was synthesized to a higher degree of polymerization since it was not intended to produce a supramolecular effect. Composites of polypeptides 4-6 and a cobalt(II) terpyridine complex ([COOII $\left.(\mathrm{MeO}-\text { tery })_{2}\right]^{2+}$ ) were obtained by mixing solutions of the respective compounds, followed by precipitation of the resulting composites, in which the counter anion of the $\left[\mathrm{Co}^{\mathrm{II}}(\mathrm{MeO}-\text { tery })_{2}\right]^{2+}$ was replaced by 
polyglutamates. Elemental analysis indicated the presence of water molecules in the final products and suggested the following formulae: $4 /\left[\mathrm{Co}^{\mathrm{II}}(\mathrm{MeO}-\text { terpy })_{2}\right] \cdot \mathrm{H}_{2} \mathrm{O}, 5 /\left[\mathrm{Co}^{\mathrm{II}}(\mathrm{MeO}-\text { terpy })_{2}\right] \cdot 3 \mathrm{H}_{2} \mathrm{O}$, and 6/[Co $\left.\mathrm{Co}^{\mathrm{II}}(\mathrm{MeO} \text {-terpy })_{2}\right] \cdot 4 \mathrm{H}_{2} \mathrm{O}$.

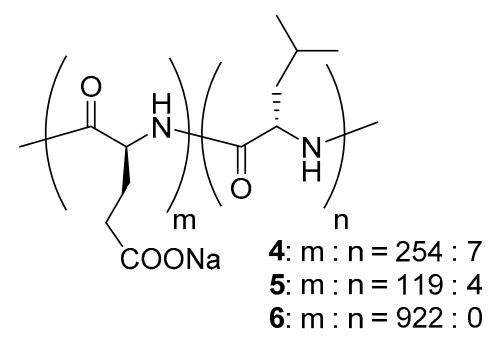

$(\mathrm{Glu})_{\mathrm{m}}-$ block-(Leu)

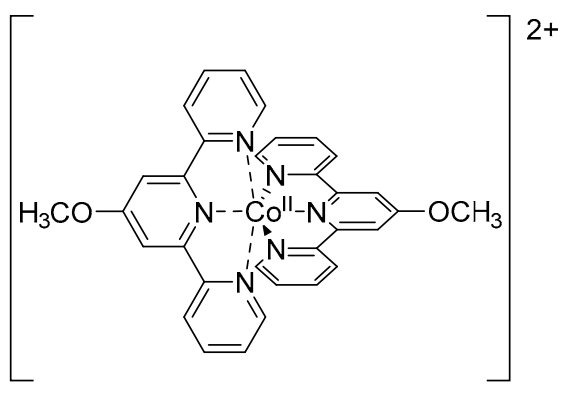

$\left[\mathrm{Coll}(\mathrm{MeO}-\text { terpy })_{2}\right]^{2+}$

Figure 8. The structures of diblock copolypeptide amphiphiles 4 and 5, polypeptide 6, and the cobalt(II) terpyridine complex $\left[\mathrm{Co}^{\mathrm{II}}(\mathrm{MeO}-\text { terpy })_{2}\right]^{2+}$.

The morphologies of the supramolecular structures generated in dispersions of these complexes were subsequently assessed by TEM. The TEM image of 4/[C $\left.\mathrm{Co}^{\mathrm{II}}(\mathrm{MeO} \text {-terpy })_{2}\right]$ following transfer to a carbon-coated $\mathrm{Cu}$ grid exhibited rectangular structures with widths of $700 \mathrm{~nm}$ to $6 \mathrm{~mm}$, while $5 /\left[\mathrm{Co}^{\mathrm{II}}(\mathrm{MeO} \text {-terpy })_{2}\right]$ showed nanostructures with widths ranging from $500 \mathrm{~nm}$ to $2 \mathrm{~mm}$.

High-resolution scanning transmission electron microscopy coupled with energy dispersive X-ray spectroscopy (HR-STEM-EDX) also confirmed that the composites consisted of cobalt(II) complexes and polymers. Figure 9 presents STEM-EDX mapping results (Figure 9b, Co; Figure 9c, O) for a nanocomposite of 4 within the boxed area indicated in Figure 9a. These data confirm the formation of nanostructures in which the cobalt complex and the amphiphile are evenly matched. Composite 6/[C $\left.\mathrm{Co}^{\mathrm{II}}(\mathrm{MeO}-\text { terpy })_{2}\right]$ did not show a specific structure in TEM observations, indicating that combinations of 6 and metal complexes did not form supramolecular structures. Samples of the composites in water were freeze-dried and wide-angle X-ray scattering (WAXS) analysis of the powdered composites was performed, during which no crystalline peaks were observed. This lack of peaks indicated the presence of an amorphous phase in the rectangular supramolecular structures. In addition, small angle X-ray scattering (SAXS) analysis showed the formation of nanostructures of various sizes, which was consistent with the nanostructures having widths of several hundred nm and several $\mu \mathrm{m}$ observed via TEM and dynamic light scattering (DLS).
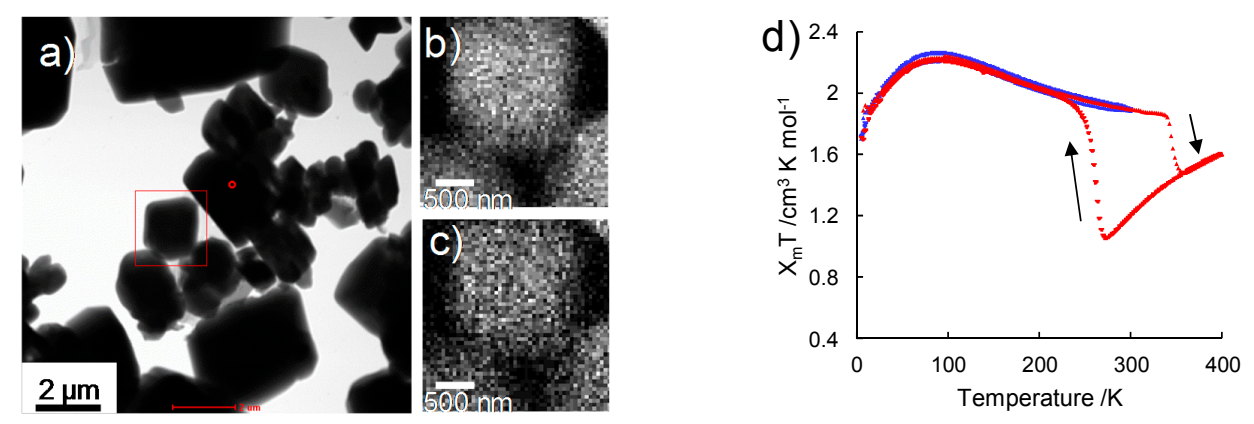

Figure 9. (a) STEM image and (b) Co and (c) O STEM-EDX maps of 4/[Co $\left.{ }^{\mathrm{II}}(\mathrm{MeO}-\text { terpy })_{2}\right]$ within the red square shown in $(\mathbf{a}) ;(\mathbf{d}) \chi_{\mathrm{m}} \mathrm{T}$ versus $\mathrm{T}$ for $4 /\left[\mathrm{Co}^{\mathrm{II}}(\mathrm{MeO} \text {-terpy })_{2}\right]$ on warming $(\boldsymbol{\Delta})$ and cooling $(\boldsymbol{\nabla})$. The blue and red plots indicate the first and second cycles, from $5 \mathrm{~K}$ to $300 \mathrm{~K}$ and $400 \mathrm{~K}$, respectively. Adapted with permission from J. Mater. Chem. C 2015, 3, 7779-7783. Copyright @ 2015, Royal Society of Chemistry. 
The variations in the magnetic susceptibilities of 4/[CoII $\left.(\mathrm{MeO}-\text { terpy })_{2}\right], 5 /\left[\mathrm{Co} \mathrm{II}(\mathrm{MeO}-\text { terpy })_{2}\right]$ and $\mathbf{6} /\left[\mathrm{Co}^{\mathrm{II}}(\mathrm{MeO} \text {-terpy })_{2}\right]$ with temperature were also examined. Composite $4 /\left[\mathrm{Co}^{\mathrm{II}}(\mathrm{MeO} \text {-terpy })_{2}\right]$ was found to remain in the HS state at all temperatures and exhibited a $\chi_{\mathrm{m}} \mathrm{T}$ value within the range of $1.69-2.25 \mathrm{~cm}^{3} \cdot \mathrm{K} \cdot \mathrm{mol}^{-1}$ over the temperature range of $5-300 \mathrm{~K}$ (see the blue plot in Figure 9d). During further heating up to $400 \mathrm{~K}$, the $\chi_{\mathrm{m}} \mathrm{T}$ value was found to decrease at $337 \mathrm{~K}$, which is consistent with the loss of water molecules (the red plot in Figure 9d). However, after annealing, the pre-heated compound displayed markedly different behavior. On cooling, the $\chi_{\mathrm{m}} \mathrm{T}$ value gradually decreased from $1.60 \mathrm{~cm}^{3} \cdot \mathrm{K} \cdot \mathrm{mol}^{-1}$ at $400 \mathrm{~K}$ to $1.05 \mathrm{~cm}^{3} \cdot \mathrm{K} \cdot \mathrm{mol}^{-1}$ at $274 \mathrm{~K}$, representing normal thermal SCO behavior (the red plot in Figure $9 \mathrm{~b}$ ). Upon further cooling, the $\chi_{\mathrm{m}} \mathrm{T}$ value increased abruptly below the $\mathrm{T}_{1 / 2} \downarrow$ value of $260 \mathrm{~K}$, to 1.96 at $222 \mathrm{~K}$. Below this temperature, $\chi_{\mathrm{m}} \mathrm{T}$ varied between 1.70 and $2.20 \mathrm{~cm}^{3} \mathrm{~K} \cdot \mathrm{mol}^{-1}$ in the temperature range between 5 and $220 \mathrm{~K}$. With subsequent heating, the $\chi_{\mathrm{m}} \mathrm{T}$ value abruptly dropped $\left(\mathrm{T}_{1 / 2} \uparrow=345 \mathrm{~K}\right)$, indicating a transition from HS to LS. Finally, the $\chi_{\mathrm{m}} \mathrm{T}$ value gradually increased between 361 and $400 \mathrm{~K}$. The wide thermal hysteresis loop $(\Delta \mathrm{T}=85 \mathrm{~K})$ near room temperature was maintained through successive thermal cycles. Thus, reverse spin transition was exhibited by the composite in its solvated state based on intermolecular interactions among the metal complexes [49-53]. Composites 5/[C $\left.\mathrm{Co}^{\mathrm{II}}(\mathrm{MeO}-\text { terpy })_{2}\right]$ and 6/[Co $\left.{ }^{\mathrm{II}}(\mathrm{MeOterpy})_{2}\right]$ also showed abnormal reverse spin transitions during heating and cooling cycles (5-300-5-400-5 K). Reversibility between the HS and LS states in the reverse spin transition, however, was dependent on the polymer employed. The diblock copolypeptide amphiphile 4 evidently possessed a suitable degree of polymerization and a balance between hydrophilic and hydrophobic portions, leading to perfect reversibility between HS and LS states, allowing reverse spin transition. The $\left[\mathrm{Co}^{\mathrm{II}}(\mathrm{MeO}-\text { terpy })_{2}\right]^{2+}$ complex with $\mathrm{BF}_{4}{ }^{-}$anions is typically observed to undergo a gradual SCO transition centered around $\mathrm{T}_{1 / 2}=100-300 \mathrm{~K}$ [54]. During this process, water molecules in the solvent have been found to play an important role in the SCO behavior, due to either two-step SCO (involving an $\mathrm{H}_{2} \mathrm{O}$-solvated complex) or one-step SCO (via a non-solvated complex). In addition, reverse spin transition can be achieved as the result of an organic-solvated metal complex in solvents such as acetone, in association with a structural phase transition [54]. These prior results suggest that the SCO of aqueous dispersions of solid composites of polymers and a cobalt(II) terpyridine complex should be accompanied by a transition between solvated and non-solvated phases, since the metal complex is dispersed in the amphiphilic polypeptide-induced nanostructure. Therefore, reversible reverse spin transition is thought to result from the balance between the amorphous diblock copolypeptide amphiphile and the loose packing of the cobalt(II) terpyridine complexes (Figure 10) [36].

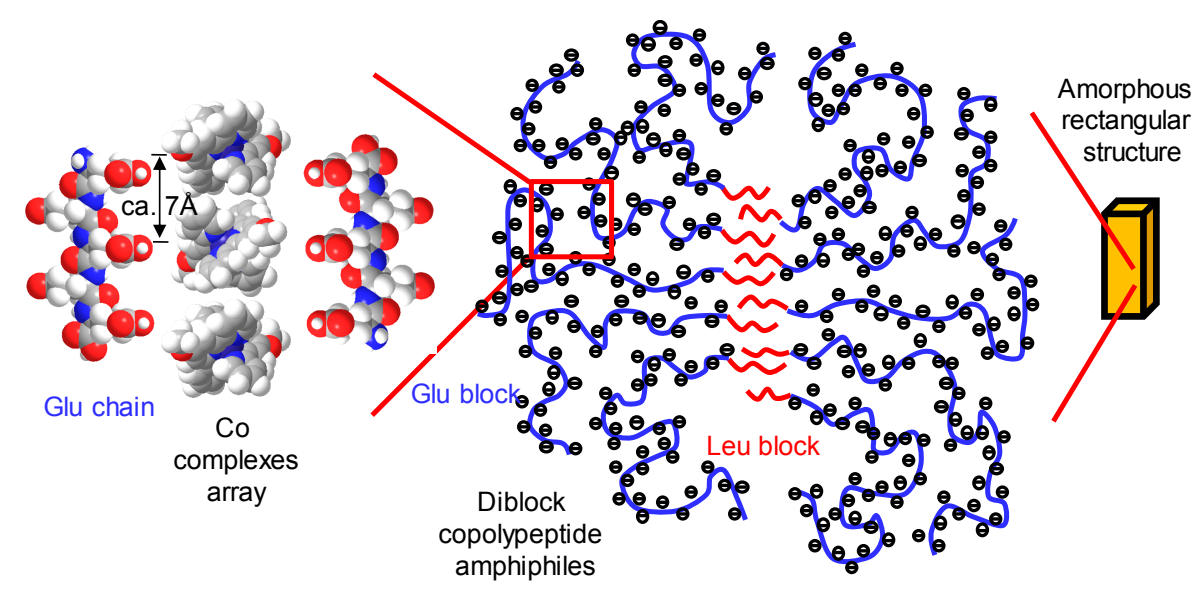

Figure 10. An illustration of the self-assembly of diblock copolypeptide amphiphile/[Co $\mathrm{CI}^{\mathrm{II}} \mathrm{MeO}-$ terpy $)_{2}$ ] complexes, demonstrating the formation of a rectangular structure from a diblock copolypeptide amphiphile with an amorphous structure. 
This work demonstrated that composites consisting of a cobalt(II) terpyridine complex with diblock copolypeptide amphiphiles generate supramolecular structures in water. The formation of these nanostructures results in the evolution of morphologies ranging in size from sub-nanometer to several micrometers. Moreover, these supramolecular composites display reverse spin transition depending on the polypeptide structure. Changes in both the morphology and magnetic properties of these materials can be induced by variations in the temperature and solvated phase.

\subsection{Fe-Complexes with Diblock Copolypeptide Amphiphiles}

Our group has also demonstrated a new type of nanocomposite based on the iron(II) complex [Fe ${ }^{\mathrm{II}}(\mathrm{ppi})_{2}(\mathrm{NCS})_{2}$ ] (2-pyridyl-N-(phenyl)methylamine (ppi); Figure 11) [59-61] with a low critical solution temperature (LCST), using diblock copolypeptide amphiphiles and SCO complexes. This work demonstrated the possibility of synthesizing multifunctional nanocomposites with metastable properties as well as the formation of cooperative nanocomposites that change spin state switching in solution [37].

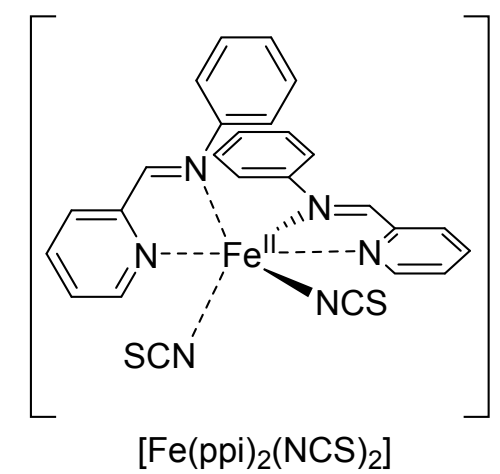

Figure 11. The structure of the iron(II) complex $\left[\mathrm{Fe}^{\mathrm{II}}(\mathrm{ppi})_{2}(\mathrm{NCS})_{2}\right]$.

Composites of polypeptides $4-6$ with $\left[\mathrm{Fe}^{\mathrm{II}}(\mathrm{ppi})_{2}(\mathrm{NCS})_{2}\right]$ were synthesized by mixing solutions of the respective compounds, followed by dispersion of hydrophobic $\left[\mathrm{Fe}^{\mathrm{II}}(\mathrm{ppi})_{2}(\mathrm{NCS})_{2}\right]$, and by dissolution of the resulting composites in water. The molar ratio between the metal complex and block copolypeptide amphiphile in each mixture was 250:4, meaning that the molar ratio between the metal complex and the leucine units was ca. 1:2. Although polypeptide 6 was composed of sodium polyglutamate without polyleucine, the hydrophobic metal complex was found to be soluble in an aqueous solution of $\mathbf{6}$. This result indicates that the metal complex was able to combine with the charge-neutralized sodium polyglutamate in water at this molar ratio during the preparation stage. Quantities of 4/[Fe $\mathrm{FI}^{\mathrm{II}}$ ppi $\left.)_{2}(\mathrm{NCS})_{2}\right], 5 /\left[\mathrm{Fe}^{\mathrm{II}}(\mathrm{ppi})_{2}(\mathrm{NCS})_{2}\right]$ and $\mathbf{6} /\left[\mathrm{Fe}^{\mathrm{II}}(\mathrm{ppi})_{2}(\mathrm{NCS})_{2}\right]$ were all obtained by lyophilization. Dissolving $4 /\left[\mathrm{Fe}^{\mathrm{II}}(\mathrm{ppi})_{2}(\mathrm{NCS})_{2}\right]$ in room temperature water at a concentration of $2 \mathrm{mM}$ (on the basis of $\mathrm{Fe}^{\mathrm{II}}$ ions) at $278 \mathrm{~K}$ gave a dark-purple solution (Figure 12a). This result indicated both inclusion of the metal complex and the formation of a homogeneous dispersion of the complex. The $\mathbf{5} /\left[\mathrm{Fe}^{\mathrm{II}}(\mathrm{ppi})_{2}(\mathrm{NCS})_{2}\right]$ and $\mathbf{6} /\left[\mathrm{Fe}^{\mathrm{II}}(\mathrm{ppi})_{2}(\mathrm{NCS})_{2}\right]$ composites also dispersed in water at $278 \mathrm{~K}$ to give dark-purple solutions, suggesting that these composites were dispersed on the molecular level. Figure $12 \mathrm{~b}$ shows the UV-vis absorption spectra of $4 /\left[\mathrm{Fe}^{\mathrm{II}}(\mathrm{ppi})_{2}(\mathrm{NCS})_{2}\right]$ in water at various temperatures. Specific absorptions are evident at $278 \mathrm{~K}$ (a peak at $578 \mathrm{~nm}$ with a shoulder around $530 \mathrm{~nm}$ ) that are characteristic of the LS Fe ${ }^{\mathrm{II}}$ complex and are attributed to metal-to-ligand charge transfer (MLCT) bands [59]. Without the polypeptide, the hydrophobic, lipophilic $\left[\mathrm{Fe}^{\mathrm{II}}(\mathrm{ppi})_{2}(\mathrm{NCS})_{2}\right]$ cannot be dissolved in water, and therefore transparent, colored aqueous solutions can provide evidence for nanostructures in water. The development of nanostructures requires the supramolecular aggregation resulting from additional intermolecular interactions. 


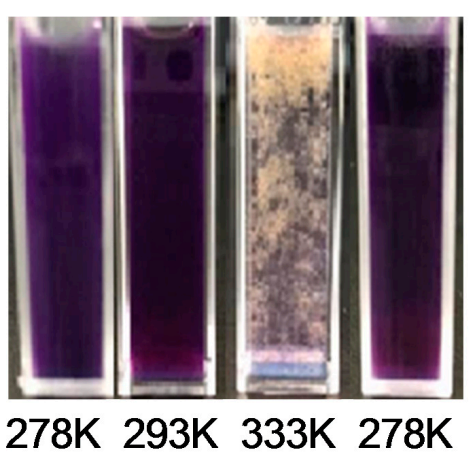

(a)

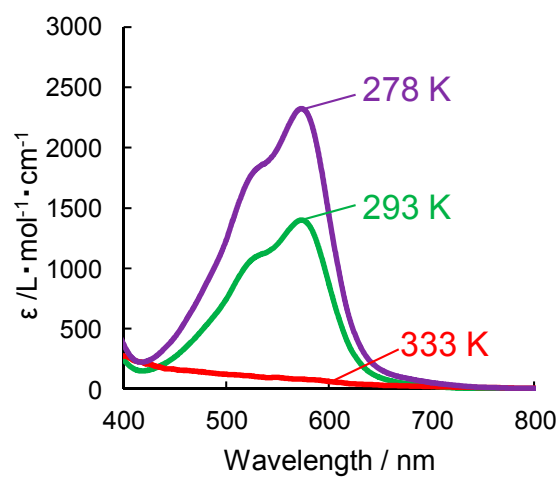

(b)

Figure 12. (a) Photographic images of aqueous solutions of $4 /\left[\mathrm{Fe}^{\mathrm{II}}(\mathrm{ppi})_{2}(\mathrm{NCS})_{2}\right]$ during heating and cooling. These show a dark purple phase at $278 \mathrm{~K}$ to $293 \mathrm{~K}$, a yellow phase at $333 \mathrm{~K}$ during a heating cycle, and a dark purple phase at $278 \mathrm{~K}$ during a cooling cycle; (b) The temperature dependence of the absorption intensity at $578 \mathrm{~nm}$ of $4 /\left[\mathrm{Fe}^{\mathrm{II}}(\mathrm{ppi})_{2}(\mathrm{NCS})_{2}\right]$. Adapted with permission from Polymer, DOI:10.1016/j.polymer.2016.12.079. (c) 2017 Elsevier Ltd. All rights reserved.

When the dark-purple solution of $4 /\left[\mathrm{Fe}^{\mathrm{II}}(\mathrm{ppi})_{2}(\mathrm{NCS})_{2}\right]$ is heated above $293 \mathrm{~K}$, the absorption intensity of the LS complex is reduced and a precipitate appears. A yellow precipitate is obtained at $333 \mathrm{~K}$, the color of which indicates the formation of a HS complex via an LCST-type transition (Figure 12a). The precipitation of the HS complexes by heating (Figure 12a) evidently occurs as a consequence of increased junctions (that is, contacts and interactions) between the bundled polypeptide and iron(II) complexes, possibly caused by a hydration-dehydration process. The $\left[\mathrm{Fe}^{\mathrm{II}}(\mathrm{ppi})_{2}(\mathrm{NCS})_{2}\right]$ complex and its derivatives are typically observed to undergo gradual SCO with a transition centered around $\mathrm{T}_{\mathrm{sc}}=\mathrm{ca} .150 \mathrm{~K}[60,61]$. During this process, interactions between iron complexes in the crystal have been found to play an important role in the SCO behavior, due to intermolecular repulsion between ligand molecules [62-64]. In addition, SCO in conjunction with a structural transition can be achieved through the application of physical pressure to crystals [65].

Figure 13 shows TEM images of $4 /\left[\mathrm{Fe}^{\mathrm{II}}(\mathrm{ppi})_{2}(\mathrm{NCS})_{2}\right]$ transferred from aqueous solution to a carbon-coated $\mathrm{Cu}$ grid. At $278 \mathrm{~K}$, various poorly defined structures are seen, including sphere-like structures (Figure 13a). In contrast, at $333 \mathrm{~K}$, well-developed sheet-like morphologies appear (Figure 13b), resulting from the aggregation of the nanocomposite due to passing through the LCST. The thermoresponsive nanocomposite $4 /\left[\mathrm{Fe}^{\mathrm{II}}(\mathrm{ppi})_{2}(\mathrm{NCS})_{2}\right]$ thus undergoes assembly due to the extension of the polypeptide chain and the hydrophobic interactions of the iron complexes. Below the LCST of the nanocomposite (ca. $313 \mathrm{~K}$ ), the interactions between polypeptide chains are weak. It is also noteworthy that, above the LCST, two-dimensional sheets with widths of several $\mu \mathrm{m}$ are self-assembled as the temperature increased, in which sheet structures with widths of several micrometers are evident (Figure 13b). The $4 /\left[\mathrm{Fe}^{\mathrm{II}}(\mathrm{ppi})_{2}(\mathrm{NCS})_{2}\right]$ sheet structures observed in TEM images are several times the length of the diblock copolypeptide amphiphiles. These structures are therefore composed of multiple strands of linear and/or stacked polypeptides combined with the metal complex, leading to SCO in conjunction with an LCST-type transition.

Supramolecular structures on the sub-nanometer to micrometer scale were observed using TEM, DLS, and SAXS, indicating that the hydrophobic interactions of the Leu moieties (Figure 14a) determine the intermolecular interactions of the composites. Nanocomposites formed between metal complexes and polypeptides in water have typically been found to be sensitive to the hydrophilic/hydrophobic balance of the composite. Thus, one possible arrangement among the metal complexes that can be proposed is moderate packing of $1 \mathrm{D}$ or 2D sheets (Figure 14b). The close-packed structure of $\left[\mathrm{Fe}^{\mathrm{II}}(\mathrm{ppi})_{2}(\mathrm{NCS})_{2}\right]$ complexes that exhibit SCO phenomena with an LCST-type transition obtained from crystallographic data is a $2 \mathrm{D}$ array of metal complexes, which results in a loose packing 
arrangement. In this structure, the iron(II) complexes are aligned with an average separation between nearest molecules of 6-7 $\AA$, which is consistent with the distance between the neighboring Leu units (ca. $0.7 \mathrm{~nm}$, as estimated by the CPK model; Figure 14b) when polyleucine partially forms a $\beta$ sheet with an all-trans conformation. Therefore, it is believed that SCO with an LCST-type transition can result from various nanostructures and aggregated structures formed from the amorphous diblock copolypeptide amphiphiles and the loose packing of the $\left[\mathrm{Fe}^{\mathrm{II}}(\mathrm{ppi})_{2}(\mathrm{NCS})_{2}\right]$ complexes (Figure 14c) [37].

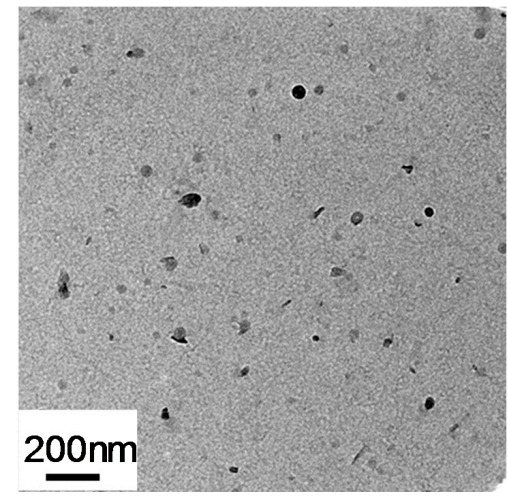

(a)

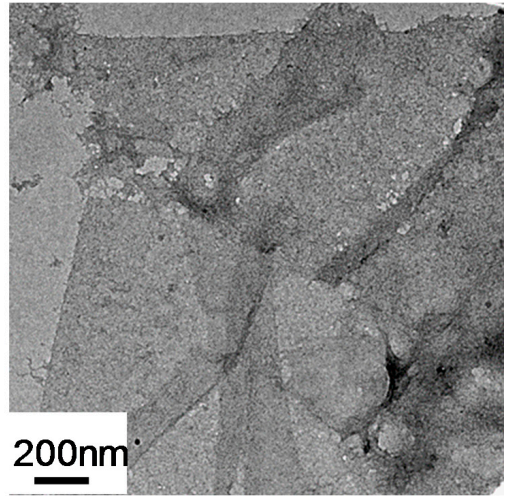

(b)

Figure 13. HR-TEM images of $4 /\left[\mathrm{Fe}^{\mathrm{II}}(\mathrm{ppi})_{2}(\mathrm{NCS})_{2}\right]$ samples prepared from water dispersions at (a) $278 \mathrm{~K}$ and (b) $333 \mathrm{~K}$. Adapted with permission from Polymer, DOI:10.1016/j.polymer.2016.12.079. (c) 2017 Elsevier Ltd. All rights reserved.

The results presented thus far demonstrate that composites consisting of $\left[\mathrm{Fe}^{\mathrm{II}}(\mathrm{ppi})_{2}(\mathrm{NCS})_{2}\right]$ complexed with diblock copolypeptide amphiphiles generate supramolecular structures in water. The formation of these nanostructures results in the evolution of morphologies ranging in size from sub-nanometer to several micrometers. Moreover, these supramolecular composites display an unusual SCO phenomenon with an LCST-type transition, depending on the polypeptide structures. Changes in the morphological, spectral, and liquid properties of these materials can be induced by variations in the intermolecular interactions through incorporating hydrophobic parts.

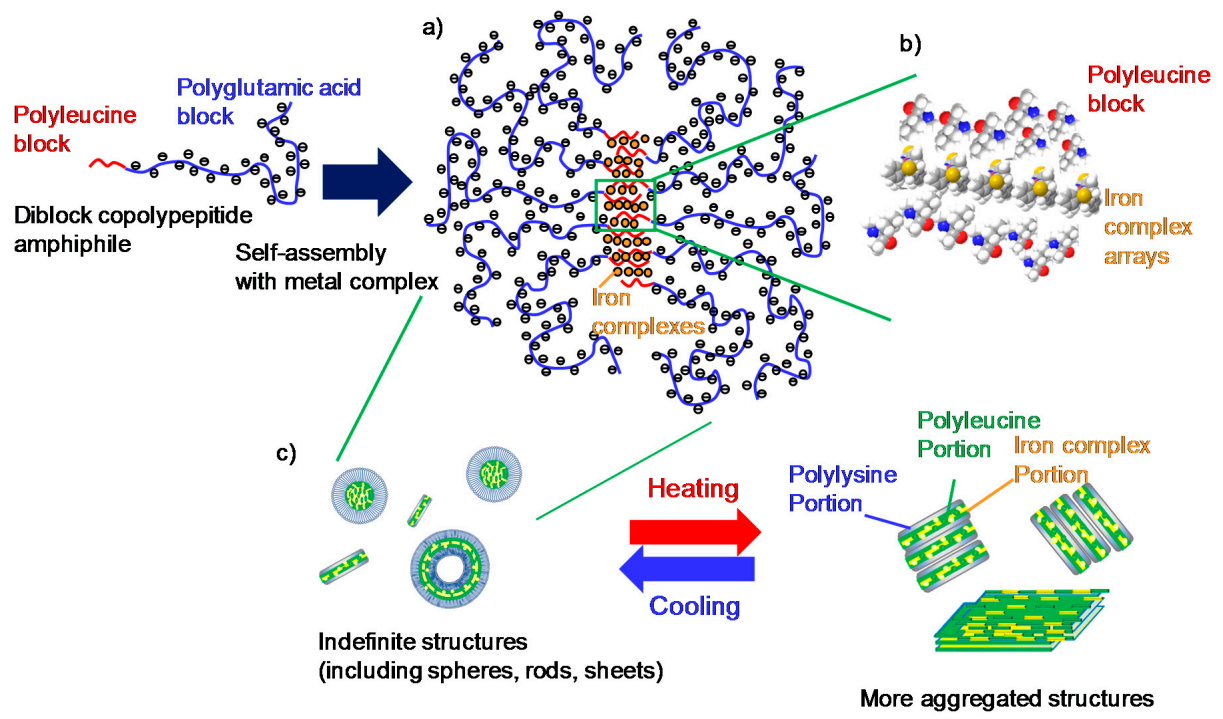

Figure 14. Hierarchical illustration of the self-assembly of the diblock copolypeptide amphiphile complex $\left.4 /\left[\mathrm{Fe}^{\mathrm{II}} \text { (ppi }\right)_{2}(\mathrm{NCS})_{2}\right]$, showing the manner in which diblock copolypeptide amphiphiles with iron(II) complexes $(\mathbf{a}, \mathbf{b})$ form nanostructures with LCST-type transitions (c). 


\section{Conclusions}

The integration of amphiphile-directed self-assembly and the chemistry of SCO complexes has led to the development of dynamic supramolecular assemblies. Imparting an amphiphilic nature to supramolecules has been found to drive their hierarchical self-assembly. Weak forces such as hydrophobic, hydrogen bonding, van der Waals, and intermolecular interactions evidently play a pivotal role in the determination of the supramolecular architecture, in contrast to reports published during earlier supramolecular chemistry studies. This combinatorial supramolecular approach is also an effective means of developing functional nanomaterials incorporating magnetic metal complexes. The combination of supramolecular nanoarchitectures and metastable engineering should allow new approaches to the design of nanomaterials.

In addition to these nanocomposite techniques, synthetic biomolecules also provide powerful scaffolds for the construction of nanoarchitectures. Therefore, well-designed nanoarchitectures may be fabricated from naturally-occurring lipids, peptides, sugars, and similar compounds. In particular, these materials hierarchically self-assemble into mesoscopic architectures with unique morphologies. This approach is simple and much easier than methods previously devised for supermolecule construction. Supramolecular assemblies having such functional components are anticipated to find increased applications in future.

Finally, it appears that the generation of metastable electronic structures based on self-assembly will be an important issue in nanochemistry. Studies of amphiphilic metal complexes have shown that discrete inorganic complexes can form self-assembling nanoarchitectures in solution, the electronic structures of which are tunable with the aid of amphiphilic molecular assemblies. The dynamic formation of various nanocomposite architectures and networks has been an unexpected result of some of this work. These unique self-assembly properties are not accessible from isolated coordination polymers or thermodynamically stable supramolecular chemistry. The growth of metastable networks in this manner is reminiscent of many central processes that occur in living systems. Thus, we envisage that self-assembling nanoarchitectures will be applied to the design of biomimetic networks that display growth and self-organization in response to external stimuli. These self-assembling systems would contribute to the development of chemical learning systems. They may also provide an opportunity to design molecular (or supramolecular) machines, a new field of molecularly organized chemistry that integrates element blocks [66] to allow transduction, translation, amplification, chemical or physical outputs, dynamic control, and self-propagation.

Acknowledgments: This work was financially supported in part by a Grant-in-Aid for Young Scientists (A) (No. 24685019) and a Grant-in-Aid for Scientific Research on Innovative Areas (New polymeric materials based on element-blocks, \#2401) (Nos. 25102547 and 15H00770). Keita Kuroiwa is also grateful for the financial support of The Canon Foundation (No. K16-0146) and for a research grant from Sojo University (No. RT02000001).

Conflicts of Interest: The authors declare no conflicts of interest.

\section{References}

1. Gispert, J.R. Coordination Chemistry; Wiley-VCH: Weinheim, Germany, 2008.

2. Lippard, S.J.; Berg, J.M. Principles of Bioinorganic Chemistry; University of Science Books: Mill Valley, CA, USA, 1994.

3. Anastassopoulou, J.; Theophanaides, T. The role of metal ions in biological systems and medicine. In Bioinorganic Chemistry: An Inorganic Perspective of Life; Nato Science Series C; Kessissoglou, D.P., Ed.; Springer: Berlin, Germany, 1995; pp. 209-218.

4. Anthony, A.; Desiraju, G.R.; Jetti, R.K.R.; Kuduva, S.S.; Madhavi, N.N.L.; Nangia, A.; Thaimattam, R.; Thallad, V.R. Crystal Engineering: Some Further Strategies. Cryst. Eng. 1998, 1, 1-18. [CrossRef]

5. Evans, D.F.; Wennerström, H. The Colloidal Domain: Where Physics, Chemistry, Biology, and Technology Meet; John Wiley \& Sons: New York, NY, USA, 1999.

6. Jones, M.N.; Chapman, D. Micelles, Monolayers and Biomembranes; John Wiley \& Sons: New York, NY, USA, 1995. 
7. Lehn, J.M. Toward self-organization and complex matter. Science 2002, 295, 2400-2403. [CrossRef] [PubMed]

8. Hanan, G.S.; Volkmer, D.; Schubert, U.S.; Lehn, J.M.; Baum, G.; Fenske, D. Coordination Arrays: Tetranuclear Cobalt(II) Complexes with [2 × 2]-Grid Structure. Angew. Chem. Int. Ed. 1997, 36, 1842-1844. [CrossRef]

9. Lehn, J.M. Supramolecular polymer chemistry-Scope and perspectives. Polym. Int. 2002, 51, 825-839. [CrossRef]

10. Fujita, M.; Yazaki, J.; Ogura, K. Preparation of a macrocyclic polynuclear complex, $\left[(\mathrm{en}) \mathrm{Pd}\left(4,4^{\prime}-\mathrm{bpy}\right)\right]_{4}\left(\mathrm{NO}_{3}\right)_{8}$ (en = ethylenediamine, bpy = bipyridine), which recognizes an organic molecule in aqueous media. J. Am. Chem. Soc. 1990, 112, 5645-5647. [CrossRef]

11. Kondo, M.; Yoshitomi, T.; Seki, K.; Matsuzaka, H.; Kitagawa, S. Three-dimensiona framework with channeling cavities for small molecules: $\left\{\left[\mathrm{M}_{2}\left(4,4^{\prime}-\mathrm{bpy}\right)_{3}\left(\mathrm{NO}_{3}\right)_{4}\right] \cdot \mathrm{xH}_{2} \mathrm{O}\right\}_{\mathrm{n}}(\mathrm{M}=\mathrm{Co}, \mathrm{Ni}, \mathrm{Zn})$. Angew. Chem. Int. Ed. 1997, 36, 1725-1727. [CrossRef]

12. Li, H.; Eddaoudi, M.; Groy, T.L.; Yaghi, O.M. Establishing microporosity in open metal-organic frameworks: Gas sorption isotherms for $\mathrm{Zn}(\mathrm{BDC})$ (BDC =1,4-benzenedi carboxylate). J. Am. Chem. Soc. 1998, 120, 8571-8572. [CrossRef]

13. Whitesides, G.M.; Mathias, J.P.; Seto, C.T. Molecular self-assembly and nanochemistry: A chemical strategy for the synthesis of nanostructures. Science 1991, 254, 1312-1319. [CrossRef] [PubMed]

14. Lehn, J.M. Supramolecular Chemistry: Concept and Perspectives; Wiley-VCH: Weinheim, Germany, 1995.

15. Awod, J.L.; Davies, J.E.D.; MacNicol, D.M.; Vögtle, F.; Lehn, J.M. Comprehensive Supramolecular Chemistry; Pergamon: Oxford, UK, 1996; Volume 9.

16. Whitesides, G.M.; Grzybowski, B. Self-assembly at all scales. Science 2002, 295, 2418-2421. [CrossRef] [PubMed]

17. Armand, F.; Badoux, C.; Bonville, P.; Ruaudel-Teixier, A.; Kahn, O. Langmuir-Blodgett Films of Spin Transition Iron(II) Metalloorganic Polymers. 1. Iron(II) Complexes of Octadecyl-1,2,4-triazole. Langmuir 1995, 11, 3467-3472. [CrossRef]

18. Soyer, H.; Dupart, E.; Gómez-García, C.J.; Mingotaud, C.; Delhaès, P. First Magnetic Observation of a Spin Crossover in a Langmuir-Blodgett Film. Adv. Mater. 1999, 11, 382-384. [CrossRef]

19. Soyer, H.; Mingotaud, C.; Boillot, M.L.; Delhaes, P. Spin Crossover of a Langmuir-Blodgett Film Based on an Amphiphilic Iron(II) Complex. Langmuir 1998, 14, 5890-5895. [CrossRef]

20. Roubeau, O.; Agricole, B.; Clérac, R.; Ravaine, S. Triazole-Based Magnetic Langmuir-Blodgett Films: Paramagnetic to Spin-Crossover Behavior. J. Phys. Chem. B 2004, 108, 15110-15116. [CrossRef]

21. Kurth, D.G.; Lehmann, P.; Schütte, M. A route to hierarchical materials based on complexes of metallosupramolecular polyelectrolytes and amphiphiles. Proc. Natl. Acad. Sci. USA 2000, 97, 5704-5707. [CrossRef] [PubMed]

22. Shibata, T.; Kimizuka, N.; Kunitake, T. Construction of mesoscopic supramolecular assemblies consisted of hydrophobic triazole derivative and Fe(II) ion. In Proceedings of the 76th CSJ National Meeting, Yokohama, Japan, 28 March 1999; CSJ: Tokyo, Japan, 1999.

23. Fujigaya, T.; Jiang, D.L.; Aida, T. Spin crossover properties of self-assembled iron(II) complexes with alkyl-tethered triazole ligands. J. Am. Chem. Soc. 2003, 125, 14690-14691. [CrossRef] [PubMed]

24. Kuroiwa, K.; Oda, N.; Kimizuka, N. Supramolecular solvatochromism. Effect of solvents on the self-assembly and charge transfer absorption characteristics of lipid-packaged, linear mixed valence platinum complexes. Sci. Tech. Adv. Mater. 2006, 7, 629-634. [CrossRef]

25. Kuroiwa, K.; Shibata, T.; Takada, A.; Nemoto, N.; Kimizuka, N. Heat-set gel-like networks of lipophilic Co(II) triazole complexes in organic media and their thermochromic structural transitions. J. Am. Chem. Soc. 2004, 126, 2016-2021. [CrossRef] [PubMed]

26. Kuroiwa, K.; Kimizuka, N. Electrochemically controlled self-assembly of lipophilic Fe $\mathrm{II}^{\mathrm{II}}$,2,4-triazole complexes in organic media. Chem. Lett. 2010, 39, 790-791. [CrossRef]

27. Kuroiwa, K.; Shibata, T.; Sasaki, S.; Ohba, M.; Takahara, A.; Kunitake, T.; Kimizuka, N. Supramolecular control of spin crossover phenomena in lipophilic Fe(II) 1,2,4-triazole complexes. J. Polym. Sci. A Polym. Chem. 2006, 44, 5192-5202. [CrossRef]

28. Kume, S.; Kuroiwa, K.; Kimizuka, N. Photo-responsive molecular wires of Fe(II) triazole complexes in organic media and light-induced morphological transformations. Chem. Commun. 2006, 42, 2442-2444. [CrossRef] [PubMed] 
29. Matsukizono, H.; Kuroiwa, K.; Kimizuka, N. lipid-packaged linear iron(II) triazole complexes in solution: Controlled spin conversion via solvophobic self-assembly. J. Am. Chem. Soc. 2008, 130, 5622-5623. [CrossRef] [PubMed]

30. Matsukizono, H.; Kuroiwa, K.; Kimizuka, N. Self-assembly-directed spin conversion of iron(II) 1,2,4-triazole complexes in solution and their effect on photorelaxation processes of fluorescent counter ions. Chem. Lett. 2008, 37, 446-447. [CrossRef]

31. Kuroiwa, K.; Kikuchi, H.; Kimizuka, N. Spin crossover characteristics of nanofibrous Fe $\mathrm{eI}_{-1,2,4-\text { triazole }}$ complexes in liquid crystals. Chem. Commun. 2010, 46, 1229-1231. [CrossRef] [PubMed]

32. Noguchi, T.; Chikara, C.; Kuroiwa, K.; Kaneko, K.; Kimizuka, N. Controlled morphology and photoreduction characteristics of polyoxometalate(POM)/lipid complexes and the effect of hydrogen bonding at molecular interfaces. Chem. Commun. 2011, 47, 6455-6457. [CrossRef] [PubMed]

33. Kuroiwa, K.; Kimizuka, N. Self-assembly and functionalization of lipophilic metal-triazole complexes in various media. Polym. J. 2013, 45, 384-390. [CrossRef]

34. Kuroiwa, K.; Yoshida, M.; Masaoka, S.; Kaneko, K.; Sakai, K.; Kimizuka, N. Self-assembly of tubular microstructures from mixed-valence metal complexes and their reversible transformation via external stimuli. Angew. Chem. Int. Ed. 2012, 51, 656-659. [CrossRef] [PubMed]

35. Kuroiwa, K. Dynamic self-assembly from mixed-valence metal complexes and their reversible transformations by external stimuli. Kobunshi Ronbunshu 2012, 69, 485-492. [CrossRef]

36. Kuroiwa, K.; Arie, T.; Sakurai, S.; Hayami, S.; Deming, T.J. Supramolecular control of reverse spin transitions in cobalt(II) terpyridine complexes with diblock copolypeptide amphiphiles. J. Mater. Chem. C 2015, 3, 7779-7783. [CrossRef]

37. Arie, T.; Otsuka, S.; Maekawa, T.; Takano, R.; Sakurai, S.; Deming, T.J.; Kuroiwa, K. Development of hybrid diblock copolypeptide amphiphile/magnetic metal complexes and their spin crossover with lower-critical-solution-temperature(LCST)-type transition. Polymer 2017. [CrossRef]

38. Kahn, O.; Martinez, C.J. Spin-transition polymers: From molecular materials toward memory devices. Science 1998, 279, 44-48. [CrossRef]

39. Kahn, O. Chemistry and physics of supramolecular magnetic materials. Acc. Chem. Res. 2000, 33, 647-657. [CrossRef] [PubMed]

40. Kahn, O.; Köber, J.; Jay, C. Spin transition molecular materials for displays and data recording. Adv. Mater. 1992, 4, 718-728. [CrossRef]

41. Köber, J.; Codjovi, E.; Kahn, O.; Groliére, F.; Jay, C. A spin transition system with a thermal hysteresis at room temperature. J. Am. Chem. Soc. 1993, 115, 9810-9811. [CrossRef]

42. Haasnoot, J.G. Mononuclear, oligonuclear and polynuclear metal coordination compounds with 1,2,4-triazole derivatives as ligands. Coord. Chem. Rev. 2000, 200-202, 131-185. [CrossRef]

43. Haasnoot, J.G. 1,2,4-Triazoles as ligands for iron(II) high spin-low spin crossovers. In Magnetism: Supramolecular Function; Kahn, O., Ed.; Kluwer Academic Publications: Dordrecht, Netherlands, 1995; pp. 299-321.

44. Vos, G.; le Fêbre, L.A.; de Graaff, R.A.G.; Haasnoot, J.G.; Reedijk, J. Unique highspin-low-spin transition of the central ion in a linear, trinuclear iron(II) triazole compound. J. Am. Chem. Soc. 1983, 105, 1682-1683. [CrossRef]

45. Roubeau, O.; Gomez, M.A.; Balskus, E.; Kolnaar, J.J.A.; Haasnoot, J.G.; Reedijk, J. Spin-transition behaviour in chains of Fe(II) bridged by 4-substituted 1,2,4-triazoles carrying alkyl tails. New J. Chem. 2001, 25, 144-150. [CrossRef]

46. Fujigaya, T.; Jiang, D.L.; Aida, T. Spin-crossover dendrimers: Generation numberdependent cooperativity for thermal transition. J. Am. Chem. Soc. 2005, 127, 5484-5489. [CrossRef] [PubMed]

47. Fujigaya, T.; Jiang, D.L.; Aida, T. Spin-crossover physical gels: A quick thermoreversible response assisted by dynamic self-organization. Chem. Asian J. 2007, 2, 106-113. [CrossRef] [PubMed]

48. Seredyuk, M.; Gaspar, A.B.; Ksenofontov, V.; Reiman, S.; Galyametdinov, Y.; Haase, W.; Rentschler, E.; Gütlich, P. Room temperature operational thermochromic liquid crystals. Chem. Mater. 2006, 18, 2513-2519. [CrossRef]

49. Hayami., S.; Shigeyoshi, Y.; Akita, M.; Inoue, K.; Kato, K.; Osaka, K.; Takata, M.; Kawajiri, R.; Mitani, R.; Maeda, Y. Reverse spin transition triggered by a structural phase transition. Angew. Chem. Int. Ed. 2005, 44, 4899-4903. [CrossRef] [PubMed] 
50. Hayami, S.; Moriyama, R.; Shuto, A.; Maeda, Y.; Ohta, K.; Inoue, K. Spin transition at the mesophase transition temperature in a cobalt(II) compound with branched alkyl chains. Inorg. Chem. 2007, 46, 7692-7694. [CrossRef] [PubMed]

51. Hayami, S.; Murata, K.; Urakami, D.; Kojima, Y.; Akita, M.; Inoue, K. Dynamic structural conversion in a spin-crossover cobalt(II) compound with long alkyl chains. Chem. Commun. 2008, 48, 6510-6512. [CrossRef] [PubMed]

52. Hayami, S.; Kato, K.; Komatsu, Y.; Fuyuhiro, A.; Ohba, M. Unique spin transition and wide thermal hysteresis loop for a cobalt(II) compound with long alkyl chain. Dalton Trans. 2011, 40, 2167-2169. [CrossRef] [PubMed]

53. Komatsu, Y.; Kato, K.; Yamamoto, Y.; Kamihata, H.; Lee, Y.H.; Akita, F.; Kawata, S.; Hayami, S. Spin-crossover behaviors based on intermolecular interactions for cobalt(II) complexes with long alkyl chains. Eur. J. Inorg. Chem. 2012, 16, 2769-2775. [CrossRef]

54. Hayami, S.; Nakaya, M.; Ohmagari, H.; Alao, A.S.; Nakamura, M.; Ohtani, R.; Yamaguchi, R.; Kuroda-Sowa, T.; Clegg, J.K. Spin crossover behaviors in solvated cobalt(II) compounds. Dalton Trans. 2015, 44, 9345-9348. [CrossRef] [PubMed]

55. Pochan, D.J.; Pakstis, L.; Ozbas, B.; Nowak, A.P.; Deming, T.J. SANS and cryo-TEM study of self-assembled diblock copolypeptide hydrogels with rich nano-through microscale morphology. Macromolecules 2002, 35, 5358-5360. [CrossRef]

56. Novak, A.P.; Breedveld, V.; Pakstis, L.; Ozbas, B.; Pine, D.J.; Pochan, D.; Deming, T.J. Rapidly recovering hydrogel scaffolds from self-assembling diblock copolypeptide amphiphiles. Nature 2002, 417, 424-428.

57. Holowka, E.P.; Sun, V.Z.; Kamei, D.T.; Deming, T.J. Polyarginine segments in block copolypeptides drive both vesicular assembly and intracellular delivery. Nat. Mater. 2007, 6, 52-57. [CrossRef] [PubMed]

58. Yang, C.Y.; Song, B.; Ao, Y.; Nowak, A.P.; Abelowitz, R.B.; Korsak, R.A.; Havton, L.A.; Deming, T.J.; Sofroniew, M.V. Biocompatibility of amphiphilic diblock copolypeptide hydrogels in the central nervous system. Biomaterials 2009, 30, 2881-2898. [CrossRef] [PubMed]

59. Barth, P.; Schemauss, G.; Specker, H. Complexes of iron (II) with substituted 2-pyridinalphenylimines. Z. Naturforsch 1972, 27, 1149-1154.

60. Wei, H.H.; Kao, S.P.; Jean, Y.C. The effect of methyl substitution on the spinstate in solid bis(Methylsubstituted 2-pyridinalphenylimine) di(thiocyanato) iron(II). Transit. Met. Chem. 1986, 11, 405-408. [CrossRef]

61. Yu, Z. Light-induced excited spin-state trapping of the complex. Transit. Met. Chem. 1996, 21, $472-473$. [CrossRef]

62. Letard, J.F.; Guionneau, P.; Codjovi, E.; Lavastre, O.; Bravic, G.; Chasseau, D.; Kahn, O. Wide thermal hysteresis for the mononuclear spin-crossover compound cis-bis(thiocyanato)bis[N-(20-pyridylmethylene)-4(phenylethynyl) anilino]iron(II). J. Am. Chem. Soc. 1997, 119, 10861-10862. [CrossRef]

63. Oso, Y.; Ishida, T. Spin-crossover transition in a mesophase iron(II) thiocyanate complex chelated with 4-hexadecyl-N-(2-pyridylmethylene)aniline. Chem. Lett. 2009, 38, 604-605. [CrossRef]

64. Djukic, B.; Seda, T.; Gorelsky, S.I.; Lough, A.J.; Lemaire, M.T. p-Extended and sixcoordinate iron(II) complexes: Structures, magnetic properties, and the electrochemical synthesis of a conducting iron(II) metallopolymer. Inorg. Chem. 2011, 50, 7334-7343. [CrossRef] [PubMed]

65. Ksenofontov, V.; Levchenko, G.; Spiering, H.; Gütlich, P.; Letard, J.F.; Bouhedja, Y.; Kahn, O. Spin crossover behavior under pressure of $\mathrm{Fe}(\mathrm{PM}-\mathrm{L})_{2}(\mathrm{NCS})_{2}$ compounds with substituted 20-pyridylmethylene 4-anilino ligands. Chem. Phys. Lett. 1998, 294, 545-553. [CrossRef]

66. Chujo, Y.; Tanaka, K. New polymeric materials based on element-blocks. Bull. Chem. Soc. Jpn. 2015, 88, 633-643. [CrossRef]

(C) 2017 by the author. Licensee MDPI, Basel, Switzerland. This article is an open access article distributed under the terms and conditions of the Creative Commons Attribution (CC BY) license (http:/ / creativecommons.org/licenses/by/4.0/). 